\title{
Quantifying the short-term dynamics of soil organic carbon decomposition using a power function model
}

\author{
Weiping Zhou ${ }^{1,2}$, Jinhong He ${ }^{3,4}$, Dafeng Hui ${ }^{5}$ and Weijun Shen ${ }^{3 *}$
}

\begin{abstract}
Introduction: Soil heterotrophic respiration ( $R_{h}$, an indicator of soil organic carbon decomposition) is an important carbon efflux of terrestrial ecosystems. However, the dynamics of soil $R_{\mathrm{h}}$ and its empirical relations with climatic factors have not been well understood.

Methods: We incubated soils of three subtropical forests at five temperatures $\left(10,17,24,31\right.$, and $\left.38^{\circ} \mathrm{C}\right)$ and five moistures $\left(20,40,60,80\right.$, and 100\% water holding capacity (WHC)) over 90 days. $R_{h}$ was measured throughout the course of the incubation. Three types of models (log-linear, exponential, and power model) were fitted to the measurements and evaluated based on the coefficient of determination $\left(r^{2}\right)$ and Akaike Information Criterion (AIC) of the model. Further regression analysis was used to derive the empirical relations between model parameters and the two climatic factors.

Results: Among the three models, the power function model $\left(R_{\mathrm{h}}=R_{1} t^{-k}\right)$ performed the best in fitting the descending trend of soil $R_{h}$ with incubation time ( $r^{2}>0.69$ for 26 of 30 models). Both $R_{l}$ and $k$ generally increased linearly with soil temperature but varied quadratically with soil moisture in the three forest soils.

Conclusions: This study demonstrated that the power function model was much more accurate than the exponential decay model in describing the decomposition dynamics of soil organic carbon (SOC) in mineral soils of subtropical forests. The empirical relations and parameter values derived from this incubation study may be incorporated into process-based ecosystem models to simulate $R_{\mathrm{h}}$ responses to climate changes.
\end{abstract}

Keywords: Soil respiration, Subtropical forest, Moisture, Temperature, Power function, Climate change

\section{Introduction}

Soil heterotrophic respiration $\left(R_{\mathrm{h}}\right)$ is a major component of soil $\mathrm{CO}_{2}$ efflux resulting from microbial decomposition of litter and soil organic carbon (SOC) (Luo et al. 2001; Davidson and Janssens 2006; Richardson et al. 2012). Many studies about the environmental controls of $R_{\mathrm{h}}$ have been conducted over the past decades using both field experiments and laboratory incubations (Giardina and Ryan 2000; Fang et al. 2005; Curiel Yuste et al. 2007; Deng et al. 2012). Previous field observations and experiments generally characterized the diurnal, seasonal, or annual variation patterns of soil $\mathrm{CO}_{2}$ fluxes and derived their empirical relations with environmental

\footnotetext{
* Correspondence: shenweij@scbg.ac.cn

${ }^{3}$ Key laboratory of Vegetation Restoration and Management of Degraded Ecosystems, South China Botanical Garden, Chinese Academy of Sciences, Guangzhou 510650, China

Full list of author information is available at the end of the article
}

factors such as temperature and moisture (Raich and Schlesinger 1992; Bond-Lamberty and Thomson 2010; Wei et al. 2015). Although field studies have the advantage of investigating soil $\mathrm{CO}_{2}$ fluxes in less or undisturbed soils, the influential environmental factors are often confounded with each other under field conditions. For instance, the increase of soil temperature may cause the decrease of soil moisture (Kirschbaum 1995; Davidson et al. 1998). Moreover, the temperature and moisture effects may also be confounded by other biotic and abiotic factors such as substrate availability and microbial biomass (Wei et al. 2015). Laboratory incubation experiment was considered the most unbiased method to investigate intrinsic soil $R_{\mathrm{h}}$ variation patterns and underlying mechanisms (Kirschbaum 1995) because it can isolate the effects of a single process on system dynamics, which may be impossible in nature. Many lab 
incubation studies therefore have been conducted to quantify biotic and abiotic effects on soil organic matter (SOM) decomposition (Kirschbaum 1995; Dalias et al. 2001; Iqbal et al. 2009; Curtin et al. 2012). For example, researchers incubated mineral soils under certain temperatures and moistures and measured $\mathrm{CO}_{2}$ release from the soil (i.e., $R_{\mathrm{h}}$ ) at different time intervals over a given period of time (Giardina and Ryan 2000; Fang et al. 2005; Thiessen et al. 2013; Zhou et al. 2014). These data were often used to quantify the dynamics of SOM decomposition and to investigate the temperature sensitivity of soil $R_{\mathrm{h}}$ (Fierer et al. 2005; Craine and Gelderman 2011; Zhou et al. 2014).

Up to date, exponential decay model has been widely used to describe the dynamics of SOM decomposition (Fang et al. 2005; Wu et al. 2006; Ise and Moorcroft 2006; Tan and Chang 2007; Song et al. 2010; Iqbal et al. 2009; Lee et al. 2014) because of its relatively simple form and reasonable goodness of fit especially for the early stage of SOM decay (Gholz et al. 2000). The exponential decay model was first proposed by Jenny et al. (1949) and later developed by Olson (1963) to quantitatively describe the first-order kinetics of SOM decomposition. It is often used for predictive purposes based on the assumption that the decomposition rate is constant and that all material can be decomposed (Berg and McClaugherty 2014). However, Aber et al. (1990) pointed out that predictions of SOM decomposition rates using a certain model are not necessarily universally applicable. Huang and Schoenau (1997) compared linear, second-order kinetics, exponential, logarithmic, and power models in describing the short-term leaf litter decomposition dynamics. Their results showed that the exponential model was not the one with the best fit. Instead, a polynomial second-order model fitted the best for aspen leaves while a logarithmic model fitted the best for hazel and mixed leaves, indicating that different models may be suitable for different kinds of leaf litter differing in quality and quantity.

Process-based ecosystem models have been widely used to simulate ecosystem responses to climate changes, although they often require vast amount of input data for model parameterization (Hui and Luo 2004; Ise and Moorcroft 2006; Shen et al. 2008; Shen et al. 2009; Davidson et al. 2012). While process-based models are considered better at forecasting future changes, empirical models (e.g., exponential decay model) are often used to fitting observational data due to their simple forms and ease of parameter estimation (Olson 1963; Meentemeyer 1978; Zhang et al. 2008; Hui and Jackson 2009; García-Palacios et al. 2013). Furthermore, such simple empirical models (e.g., the $Q_{10}$ function describing the relationship between $R_{\mathrm{h}}$ and temperature) are the key constitutes of more sophisticated ecosystem process models (Shen et al. 2008; Shen et al. 2009). Deriving accurate empirical relations and parameter values for particular ecosystems is therefore an important step for the development and parameterization of ecosystem models (Luo et al. 2001; Hui and Luo 2004; Shen et al. 2008; Shen et al. 2009; Davidson et al. 2012; Bauer et al. 2008). Although the exponential decay model had been used to describe leaf litter decomposition process in plantation forests of southern China ( $\mathrm{Li}$ et al. 2001), few studies have derived the empirical relations between SOC dynamics and climatic factors for the mineral soils of subtropical forests. This is in spite of the fact that subtropical forests in southern China are the largest carbon sink of the country, and the soils play a critical role in the carbon balance of the region (Piao et al. 2009; Wei et al. 2015).

In this study, we incubated soils from three subtropical forests under a range of temperatures and moistures over 90 days and measured soil $R_{\mathrm{h}}$ during the course of the incubation. The main objectives were (1) to quantify the dynamics of soil $R_{\mathrm{h}}$ for various forest soils under different soil temperature and moisture treatments, (2) to test the suitability of different empirical models (e.g., log-linear, exponential, and power functions) in simulating the short-term dynamics of $R_{\mathrm{h}}$ flux or SOC decomposition, and (3) to derive the empirical relations between model parameters and soil climatic conditions.

\section{Methods}

\section{Soil sampling and incubation experimental design}

The laboratory incubation experiment was conducted at South China Botanical Garden, Chinese Academy of Sciences (CAS) in Guangzhou, China. Soils were collected at the top soil layer $(0-20 \mathrm{~cm})$ from three subtropical forests at the Heshan National Ecosystem Observation and Research Station (22 $\left.34^{\prime} \mathrm{N}, 112^{\circ} 50^{\prime} \mathrm{E}\right)$, about $80 \mathrm{~km}$ away from the Guangzhou City. The three forests included a plantation of Pinus elliottii (PE), a plantation of Schima superba (SS), and a subtropical coniferous and broadleaf mixed forest (CB). Soil total organic carbon content (TOC) were $14.8( \pm 0.26), 13.3( \pm 0.32)$, and $16.95( \pm 0.46) \mathrm{mg} \mathrm{g}^{-1}$ dry soil; total nitrogen $(\mathrm{TN})$ were $1.05( \pm 0.01), 0.99( \pm 0.02)$, and $1.22( \pm 0.02) \mathrm{mg} \mathrm{g}^{-1}$ dry soil; total phosphorus (TP) were $0.19( \pm 0.008), 0.22$ $( \pm 0.005)$, and $0.25( \pm 0.004) \mathrm{mg} \mathrm{g}^{-1}$ dry soil for PE, SS, and $\mathrm{CB}$, respectively. Soil bulk density $(\mathrm{BD})$ were $1.4 \mathrm{~g} \mathrm{~cm}^{-3}$ for PE and SS, and $1.027 \mathrm{~g} \mathrm{~cm}^{-3}$ for CB. Soil $\mathrm{pH}(\mathrm{KCl}$ extraction) were $3.58( \pm 0.08), 3.34( \pm 0.02)$, and $3.32( \pm 0.01)$ for $\mathrm{PE}, \mathrm{SS}$, and $\mathrm{CB}$, respectively. The detailed description of soil sample collection, laboratory incubation, and measurements can be found in Zhou et al. (2014). Here, we briefly described the relevant experimental design and measurements. 
In each forest, we established four plots $\left(10 \times 10 \mathrm{~m}^{2}\right)$ at least $10 \mathrm{~m}$ apart from each other to collect replicated soil samples. We randomly located five sampling spots (area $=20 \times 10 \mathrm{~cm}^{2}$ ) within each plot and collected five soil samples to the depth of $20 \mathrm{~cm}$. The five random samples were homogenized to form a composite sample for each plot. We therefore had four replicated soil samples for each forest, with each composite sample weighing about $50 \mathrm{~kg}$ in fresh weight. All soil samples were transported to the laboratory and sieved through a 2-mm sieve to remove coarse plant and mineral materials.

The laboratory incubation experiment was conducted using a full factorial design with two factors (temperature and moisture) and five treatment levels for each factor. The five temperature levels were $10,17,24,31$, and $38^{\circ} \mathrm{C}$, and the five moisture treatment levels were $20,40,60,80$, and $100 \%$ water holding capacity (WHC). The total number of treatments for each forest was 25 (five temperature treatments time five moisture treatments). Each treatment had four replicates from the four composite samples, thus resulting in 300 incubation soil samples in total (25 treatments $\times 4$ replicates $\times 3$ forest soils). Each incubation sample weighing $\sim 50 \mathrm{~g}$ of oven-dried soil was added to each Erlenmeyer flask that was covered by rubber stoppers with small holes to reduce evaporative water loss and maintain gas exchange. Soil water content was adjusted to corresponding soil moisture level by adding deionized water using a pipette. Soil temperature was controlled using the thermostat incubator (RXZ-600B, Southeast Instrument Co., Ltd., Ningbo, China). Soil $R_{\mathrm{h}}$ was measured using $\mathrm{Li}-$ 6262 infrared gas analyzer (Li-Cor Inc., Lincoln, Nebraska, USA) at the days of $1,2,3,4,6,7,13,18,27,34,41,53$, 62,74 , and 90 . It is noted here that the $R_{\mathrm{h}}$ data of SS on day 7, day 30, and day 90 had been reported in Zhou et al. (2014), which were used to assess the moisture effects on the temperature sensitivity of $R_{\mathrm{h}}$; here, the data were mainly used to derive empirical relations.

\section{Statistical modeling and analysis}

We fitted log-linear, exponential, and power function models to the $R_{\mathrm{h}}$-incubation time data pairs for all the three forest soils, and then assessed the performance of the three models based on coefficient of determination $\left(r^{2}\right)$ and Akaike Information Criterion (AIC). The $r^{2}$ is a measure of goodness of fit of the model while AIC offers a relative estimate of the information lost when a given model is used to represent the process that generates the data. Therefore, larger $r^{2}$ values represent a better goodness of fit while lower AIC values indicate a relatively higher quality of the model. The three models are as follows:

$$
\begin{aligned}
& R_{\mathrm{h}}=a+b \log (t) \\
& R_{\mathrm{h}}=a \operatorname{Exp}(b t)
\end{aligned}
$$

$$
R_{\mathrm{h}}=a t^{b}
$$

where $R_{\mathrm{h}}$ is the soil heterotrophic respiration at time $t, a$ and $b$ are two parameters.

Besides assessing the performance of different models, we tested the differences of the best model parameters among the three forest soils using analysis of variance (ANOVA). All data analyses were performed in SAS 9.3 (SAS Inc., Cary, NC).

\section{Results}

\section{Modeling the dynamics of soil $R_{\mathrm{h}}$}

Under all the temperature and moisture treatments for the three forest soils, soil $R_{\mathrm{h}}$ showed similar dynamic patterns: the highest $R_{\mathrm{h}}$ appeared in the beginning of the incubation and declined rapidly in the first 10-20 days, then leveled off eventually (Figs. 1 and 2). Although all the three models could quantitatively describe the dynamic behavior, the power function model provided the best fit for the measurements, since AIC was the lowest and $r^{2}$ the highest for the power function model compared with the other two models (Table 1). This was also consistent across all the three forest soils. For most of the power function models (26 out of $30 ; 15$ for the temperature treatments (Fig. 1) and 15 for the moisture treatments (Fig. 2)), the $r^{2}$ values were larger than 0.69 (Table 2). The power function model $\left(R_{\mathrm{h}}=R_{1} t^{-k}\right.$, with $R_{1}$ being the $R_{\mathrm{h}}$ at $t=1$ and $k$ the power) was therefore used to describe the dynamics of soil $R_{\mathrm{h}}$ for all treatments and forest soils hereafter.

For temperature treatments, soil $R_{\mathrm{h}}$ was higher under higher temperatures, particularly in the beginning of the incubation (Fig. 1). Soil $R_{\mathrm{h}}$ was the largest under the 38 ${ }^{\circ} \mathrm{C}$ treatment and the lowest under the $10{ }^{\circ} \mathrm{C}$ treatment. Among the three forest soils, PE soil had the lowest soil $R_{\mathrm{h}}$ (Fig. 1a) and CB the highest (Fig. 1c). Averaged over the 15 measurement times during the 90-day incubation, soil $R_{\mathrm{h}}$ was $0.577,0.723$ and $0.876 \mu \mathrm{g} \mathrm{C} \mathrm{g}^{-1}$ dry soil $\mathrm{h}^{-1}$ for the PE, SS, and CB forests, respectively. The power function model fitted soil $R_{\mathrm{h}}$ dynamics well at all the five temperature levels, with the $r^{2}$ ranging from 0.55 to 0.97 (Table 2). The $r^{2}$ was lower under $10^{\circ} \mathrm{C}$ than the other temperature levels, indicating a relatively poor goodness of fit of the model at a low temperature (Table 2). The initial respiration $R_{1}$ and power $k$ of the model generally increased with temperature.

For soil moisture treatments, the largest $R_{\mathrm{h}}$ appeared at the $60 \%$ WHC moisture level, followed by the $80 \%$ WHC (Fig. 2). Soil $R_{\mathrm{h}}$ was the lowest under the $20 \%$ WHC moisture level in all the three forest soils. The $r^{2}$ of power function models ranged from 0.69 to 0.92 (Fig. 2 and Table 2) and was lower under the $20 \% \mathrm{WHC}$ moisture than higher moisture levels, indicating that the power function model received a relatively poorer goodness of fit at a dry 


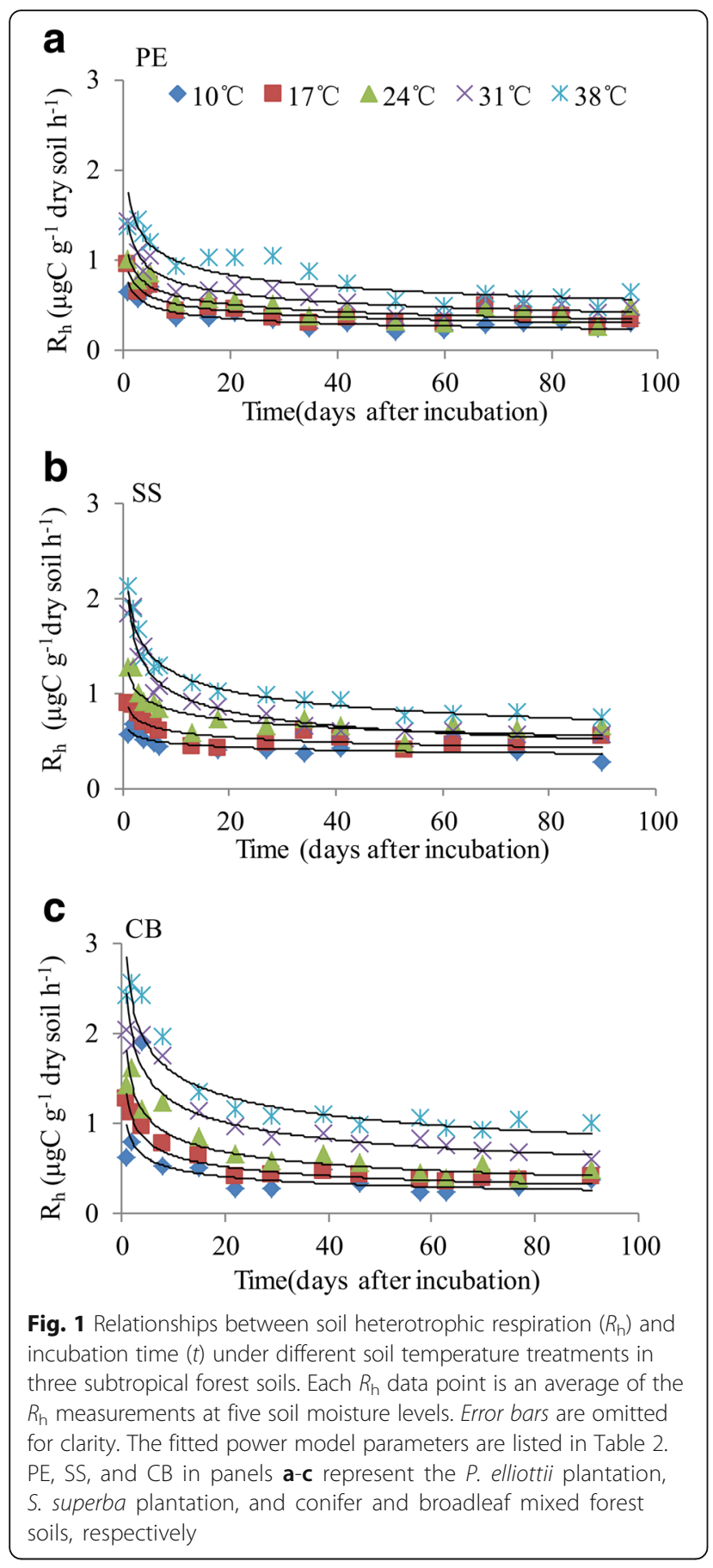

condition. The initial respiration $R_{1}$ and power $k$ were generally larger at $40-80 \%$ WHC than those at 20 and $100 \%$ WHC (Table 2), indicating that $R_{\mathrm{h}}$ declining rate was faster at moderate moisture conditions than at very dry or wet conditions.

\section{Half-life of soil $R_{\mathrm{h}}$}

While the power function model described the declining trend of $R_{\mathrm{h}}$ with incubation time well as shown in Figs. 1 and

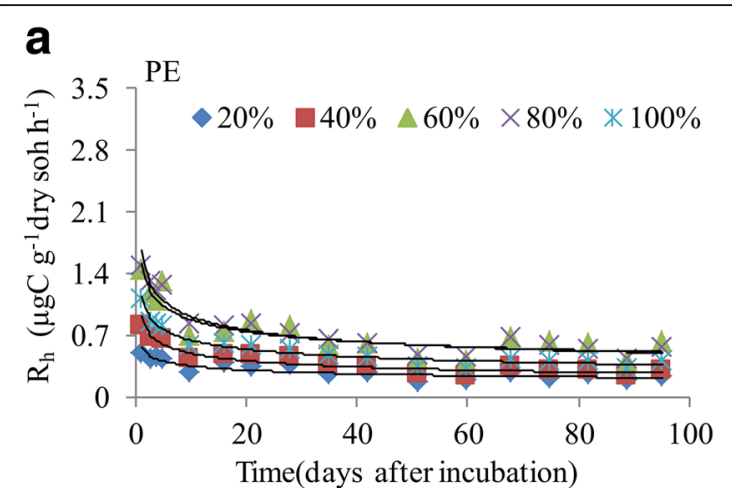

b
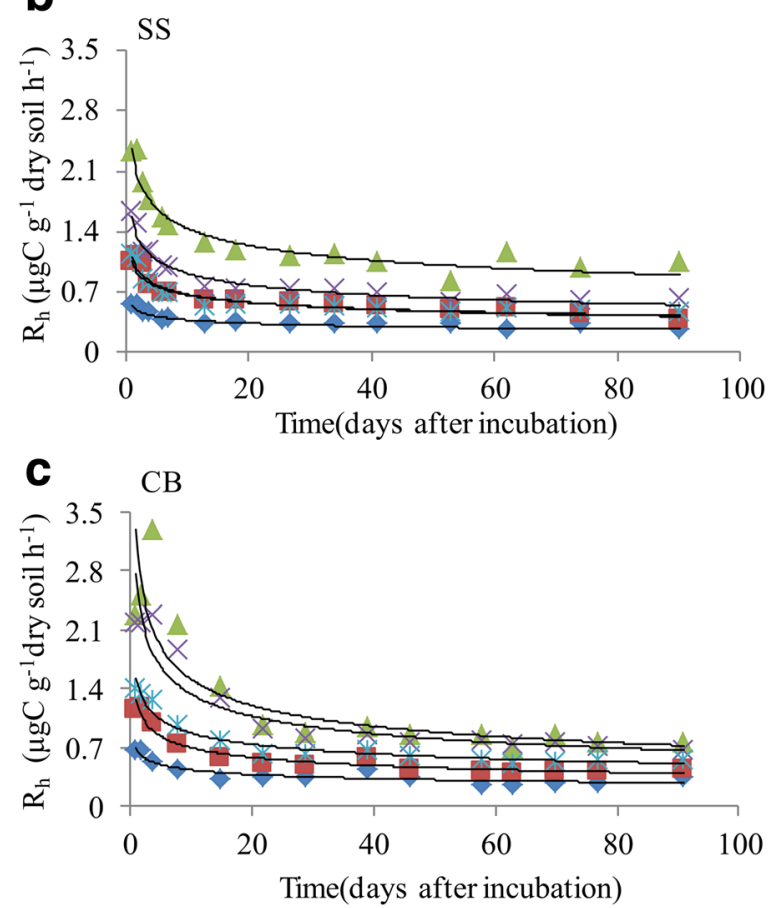

Fig. 2 Relationships between soil heterotrophic respiration $\left(R_{h}\right)$ and incubation time $(t)$ under different soil moisture treatments in three subtropical forest soils. Each $R_{\mathrm{h}}$ data point is an average of the $R_{\mathrm{h}}$ measurements at five temperature levels. Error bars are omitted for clarity. The fitted power model parameters are listed in Table 2. $\mathrm{PE}, \mathrm{SS}$, and $\mathrm{CB}$ in panels a-c represent the $P$. elliottii plantation, S. superba plantation, and conifer and broadleaf mixed forest soils, respectively

2, the half-life of soil $R_{\mathrm{h}}$ reduction (i.e., the time it takes for soil $R_{\mathrm{h}}$ to be reduced to $50 \%$ of its starting value) could provide a simple indicator of SOC decomposition rate. The shorter the half-life, the faster the SOC decomposition. Based on the power function, we estimated the half-life of soil $R_{\mathrm{h}}$ $\left(t_{1 / 2}\right)$ using the equation $t_{1 / 2}=\sqrt[k]{0.5}=e^{\ln (0.5) / k}$, with $k$ being the component as given in Eq. (3) in the method section.

The estimated $t_{1 / 2}$ of soil $R_{\mathrm{h}}$ varied from 8.3 to 175.0 days under different soil temperature and moisture 
Table 1 Comparison of three statistical models relating heterotrophic soil respiration $\left(R_{h}\right)$ to incubation time $(t)$ in three subtropical forest soils

\begin{tabular}{lllll}
\hline Model $^{\mathrm{a}}$ & & $\mathrm{PE}^{\mathrm{b}}$ & $\mathrm{SS}$ & $\mathrm{CB}$ \\
\hline Log-linear & $a, b$ & $1.0290,-0.1250$ & $1.2802,-0.1788$ & $1.8248,-0.3020$ \\
$R_{\mathrm{h}}=a+b \log (t)$ & $\mathrm{AIC}$ & -57.68 & -70.52 & -48.08 \\
& $r^{2}$ & 0.51 & 0.90 & 0.88 \\
Exponential & $a, b$ & $0.4152,-0.0207$ & $0.5894,-0.0173$ & $0.9690,-0.0267$ \\
$R_{\mathrm{h}}=a$ Exp $(b t)$ & $\mathrm{AIC}$ & -50.94 & -50.40 & -38.04 \\
& $r^{2}$ & 0.67 & 0.62 & 0.71 \\
Power & $a, b$ & $0.9754,-0.2355$ & $1.1125,-0.1862$ & $2.4384,-0.2782$ \\
$R_{\mathrm{h}}=a t^{\mathrm{b}}$ & $\mathrm{AIC}$ & -61.27 & -75.14 & -54.28 \\
& $r^{2}$ & 0.82 & 0.93 & 0.91 \\
\hline
\end{tabular}

${ }^{a}$ In deriving the impirical models, one $R_{\mathrm{h}}$ data point at each measurement day was the average of the $R_{\mathrm{h}}$ measurements under the 25 experimental treatments (i.e., 5 temperatures $\times 5$ moistures)

${ }^{\mathrm{b}} \mathrm{PE}, \mathrm{SS}$, and CB represent the P. elliottii plantation, S. superba plantation, and conifer and broadleaf mixed forest soils, respectively

treatments, but most of them were less than 20 days (Table 3). We could clearly see that the half-life of $R_{\mathrm{h}}$ was much longer under the lowest temperature $\left(10^{\circ} \mathrm{C}\right)$ and the driest moisture $(20 \% \mathrm{WHC}$ ) conditions (Table 3$)$, indicating a slower SOM decomposition under cool and dry conditions. Forest soil type also had significant effects on $t_{1 / 2}$ under different temperature $(P=0.03)$ and moisture $(P=0.04)$ treatments. The SS soil had the longest half-life of $R_{\mathrm{h}}$, followed by the PE and CB soils (Table 3), indicating that the SOM decomposition rate was slower in SS soils compared with the other two soils.

\section{Influence of soil temperature and moisture on model parameters}

The ANOVA analysis showed that there were clear differences in model parameters ( $k$ and $R_{1}$ ) among the three forest soils (Figs. 3 and 4). Under temperature treatments, forest soil type effect on initial respiration $R_{1}$ was not significant $(P=0.37)$. $k$ value was significantly influenced by forest soil type $(P=0.009)$, being significant lower in the SS soil (0.187) than in the CB (0.276) and PE (0.244) soils. Under moisture treatments, forest soil type effect on $R_{1}$ was also not significant $(P=0.36)$, but its effects on $k$ were also significant $(P=0.014)$. The $k$ value was significantly lower in the SS soil (0.190) than in the CB (0.275) and PE (0.244) soils $(P=0.007)$.

The values of $k$ and $R_{1}$ were also markedly affected by soil temperature and moisture. In all forest soils, $R_{1}$ increased linearly with the increase of soil temperature (Fig. 3). The value of $k$ also increased linearly with soil temperature in the PE and SS soils, reflecting a faster declining rate of $R_{\mathrm{h}}$ under warmer temperatures for these two soils. However, $k$ showed a quadratic response to temperature in the CB soil (Fig. 3c), indicating the optimum temperature range for soil $R_{\mathrm{h}}$ in this forest soil was narrower relative to those for the $\mathrm{PE}$ and SS soils. With respect to the soil moisture treatments, both $R_{1}$ and $k$ increased quadratically with moisture to the highest values at around $60 \% \mathrm{WHC}$ and declined at lower and higher soil moistures (Fig. 4).

\section{Discussion}

Like plant litter decomposition, SOC decomposition is a complex process involving several key components such as

Table 2 Parameters and coefficient of determination $\left(r^{2}\right)$ of the power function model fitting the change of soil heterotrophic respiration $\left(R_{h}\right)$ with incubation time in three subtropical forest soils

\begin{tabular}{|c|c|c|c|c|c|c|c|c|c|}
\hline & \multirow[b]{2}{*}{ Initial $R_{\mathrm{h}}\left(R_{1}\right)^{\mathrm{b}}$} & \multirow{2}{*}{$\begin{array}{l}\mathrm{PE}^{\mathrm{a}} \\
\text { Power }(k)^{\mathrm{b}}\end{array}$} & \multirow[b]{2}{*}{$r^{2}$} & \multicolumn{3}{|l|}{ SS } & \multicolumn{3}{|l|}{$C B$} \\
\hline & & & & Initial $R_{\mathrm{h}}\left(R_{1}\right)$ & Power (k) & $r^{2}$ & Initial $R_{\mathrm{h}}\left(R_{1}\right)$ & Power (k) & $r^{2}$ \\
\hline \multicolumn{10}{|c|}{ Temperature $\left({ }^{\circ} \mathrm{C}\right)$} \\
\hline 10 & 0.628 & 0.236 & 0.720 & 0.582 & 0.136 & 0.612 & 0.747 & 0.268 & 0.555 \\
\hline 17 & 0.768 & 0.243 & 0.793 & 0.702 & 0.134 & 0.581 & 1.137 & 0.307 & 0.946 \\
\hline 24 & 0.944 & 0.238 & 0.760 & 0.998 & 0.167 & 0.764 & 1.456 & 0.293 & 0.905 \\
\hline 31 & 1.276 & 0.253 & 0.855 & 1.647 & 0.266 & 0.963 & 2.054 & 0.268 & 0.942 \\
\hline 38 & 1.712 & 0.252 & 0.821 & 1.913 & 0.232 & 0.965 & 2.523 & 0.242 & 0.937 \\
\hline \multicolumn{10}{|c|}{ Moisture (\% water holding capacity) } \\
\hline $20 \%$ & 0.494 & 0.195 & 0.692 & 0.514 & 0.159 & 0.874 & 0.576 & 0.201 & 0.708 \\
\hline $40 \%$ & 0.847 & 0.270 & 0.858 & 1.038 & 0.206 & 0.913 & 1.179 & 0.278 & 0.917 \\
\hline $60 \%$ & 1.423 & 0.232 & 0.739 & 2.118 & 0.202 & 0.901 & 2.928 & 0.328 & 0.863 \\
\hline $80 \%$ & 1.578 & 0.266 & 0.893 & 1.262 & 0.201 & 0.891 & 2.364 & 0.314 & 0.922 \\
\hline $100 \%$ & 1.059 & 0.259 & 0.917 & 0.913 & 0.180 & 0.861 & 1.362 & 0.255 & 0.909 \\
\hline
\end{tabular}

${ }^{\mathrm{a}} \mathrm{PE}, \mathrm{SS}$, and CB represent the $P$. elliottii plantation, S. superba plantation, and conifer and broadleaf mixed forest soils, respectively

${ }^{\mathrm{b}}$ To derive the empirical relation for each temperature level, $R_{\mathrm{h}}$ under the five moisture levels were averaged; to derive that for each moisture level, $R_{\mathrm{h}}$ under the five temperature levels were averaged. All models are significant at $a=0.05$ 
Table 3 Half-life $\left(t_{1 / 2}\right)$ of soil heterotrophic respiration $\left(R_{h}\right)$ for three subtropical forest soils incubated over 90 days under five temperature and five moisture levels

\begin{tabular}{|c|c|c|c|c|c|c|}
\hline & \multicolumn{2}{|l|}{$P E^{a}$} & \multicolumn{2}{|l|}{ SS } & \multicolumn{2}{|l|}{$\mathrm{CB}$} \\
\hline & Half-life $\left(t_{1 / 2}\right)$ & $R_{h}\left(t_{1 / 2}\right)$ & Half-life $\left(t_{1 / 2}\right)$ & $R_{\mathrm{h}}\left(t_{1 / 2}\right)$ & Half-life $\left(t_{1 / 2}\right)$ & $R_{\mathrm{h}}\left(t_{1 / 2}\right)$ \\
\hline \multicolumn{7}{|c|}{ Temperature $\left({ }^{\circ} \mathrm{C}\right)$} \\
\hline 10 & 18.8 & 0.314 & 161.4 & 0.291 & 13.3 & 0.374 \\
\hline 17 & 17.3 & 0.384 & 175.0 & 0.351 & 9.6 & 0.569 \\
\hline 24 & 18.4 & 0.472 & 63.8 & 0.499 & 10.6 & 0.728 \\
\hline 31 & 15.5 & 0.638 & 13.5 & 0.823 & 13.3 & 1.027 \\
\hline 38 & 15.7 & 0.856 & 19.9 & 0.956 & 17.5 & 1.261 \\
\hline \multicolumn{7}{|c|}{ Moisture (\% water holding capacity) } \\
\hline $20 \%$ & 34.8 & 0.247 & 79.3 & 0.257 & 31.3 & 0.288 \\
\hline $40 \%$ & 13.0 & 0.423 & 29.1 & 0.519 & 12.1 & 0.590 \\
\hline $60 \%$ & 19.9 & 0.712 & 31.1 & 1.059 & 8.3 & 1.464 \\
\hline $80 \%$ & 13.6 & 0.789 & 31.4 & 0.631 & 9.1 & 1.182 \\
\hline $100 \%$ & 14.6 & 0.529 & 46.9 & 0.457 & 15.1 & 0.681 \\
\hline
\end{tabular}

${ }^{\mathrm{a}} \mathrm{PE}, \mathrm{SS}$, and CB represent the P. elliottii plantation, S. superba plantation, and conifer and broadleaf mixed forest soils, respectively

microorganisms, quantity and quality of SOC substrates, and environmental factors (Fang et al. 2005; Davidson and Janssens 2006; Zhou et al. 2014). Exponential decay model has been widely used to describe the dynamics of SOM decomposition (Paul et al. 1999; Iqbal et al. 2009), but few previous studies have tested the generality of its use in comparison with the other models. No fully controlled incubation experiments, to our knowledge, have been devoted to deriving the empirical relations between soil $R_{\mathrm{h}}$ and climatic factors for subtropical forest soils of southern China. We used soil $R_{\mathrm{h}}$ as a proxy of SOC decomposition in this study and demonstrated that the power function model was more accurate than the widely used exponential decay model in fitting the short-term dynamics of SOC decomposition in three subtropical forest soils.

To compare the dynamic behaviors between a power function model and an exponential model, we plotted the fitting curves of the two models in Fig. 5 using the parameters $(a=2.4384$ and $b=-0.2782)$ listed in Table 2 for the $\mathrm{CB}$ forest soil. The descending trend was much faster for the exponential model than that for the power function model, especially at the early stage of SOC decomposition (<13 days of incubation). We therefore argue that exponential decay models may be more suitable for describing the decomposition process of labile organic carbons (e.g., leaf litter or glucose amended in mineral soils) as have been frequently reported in literature (Blagodatskaya et al. 2009; Nottingham et al. 2009; Berg and McClaugherty 2014), whereas power function models may be more suitable for recalcitrant organic carbons require a slower decomposition process. In many process-based ecosystem models such as CENTURY (Parton et al. 1988; Paustian et al. 1992) and PALS (Reynolds et al. 2000; Shen et al. 2009), both the labile and recalcitrant SOC pool dynamics were described using exponential decay models. Based on the results of this incubation experiment and the modeling analysis, we suggest that power function models should be used to describe the dynamics of recalcitrant carbon pools.

Moreover, power function models are equally good as exponential models for that the two key model parameters $\left(R_{1}\right.$ and $\left.k\right)$ have clear ecological meanings. When log-transformed, the power function receives the form of $\ln \left(R_{\mathrm{h}}\right)=\ln \left(R_{1}\right)-k \ln (t)$. Here, power $k$ is the slope of the log-transformed linear function and therefore indicates the rate of soil $R_{\mathrm{h}}$ change. The initial respiration $R_{1}$ means the starting soil $R_{\mathrm{h}}$ at the beginning of incubation when $t=1$. In all the three forest soils, both $k$ and $R_{1}$ varied with temperature and moisture but in different patterns, which may be a reflection of the variations in substrate availability and microbial communities among different soils. It is well known that SOC decomposition is an enzyme-driven, microbe-mediated biological process (Luo et al. 2001; Craine and Gelderman 2011). At higher temperatures (e.g., 31 and $38^{\circ} \mathrm{C}$ ), microbes are usually more active and grow faster, which explains why $R_{1}$ was larger at warmer than lower temperatures (e.g., $10^{\circ} \mathrm{C}$ ). The faster growth of microbes under warmer temperatures may result in a greater carbon consumption and therefore a shorter half-life $\left(t_{1 / 2}\right)$ of $R_{\mathrm{h}}$ (Table 3). This pattern is consistent with what had been found in Nambu et al. (2008) that $t_{1 / 2}$ was inversely related to $R_{1}$. Similar to $R_{1}, k$ was also larger under higher than lower temperatures in SS and PE forests (Fig. 3a, b). The different response patterns of $k$ for the $C B$ soil (Fig. 3c) may be ascribed to the differentiated soil properties between the natural $\mathrm{CB}$ forest and the man-made SS and PE plantations. 


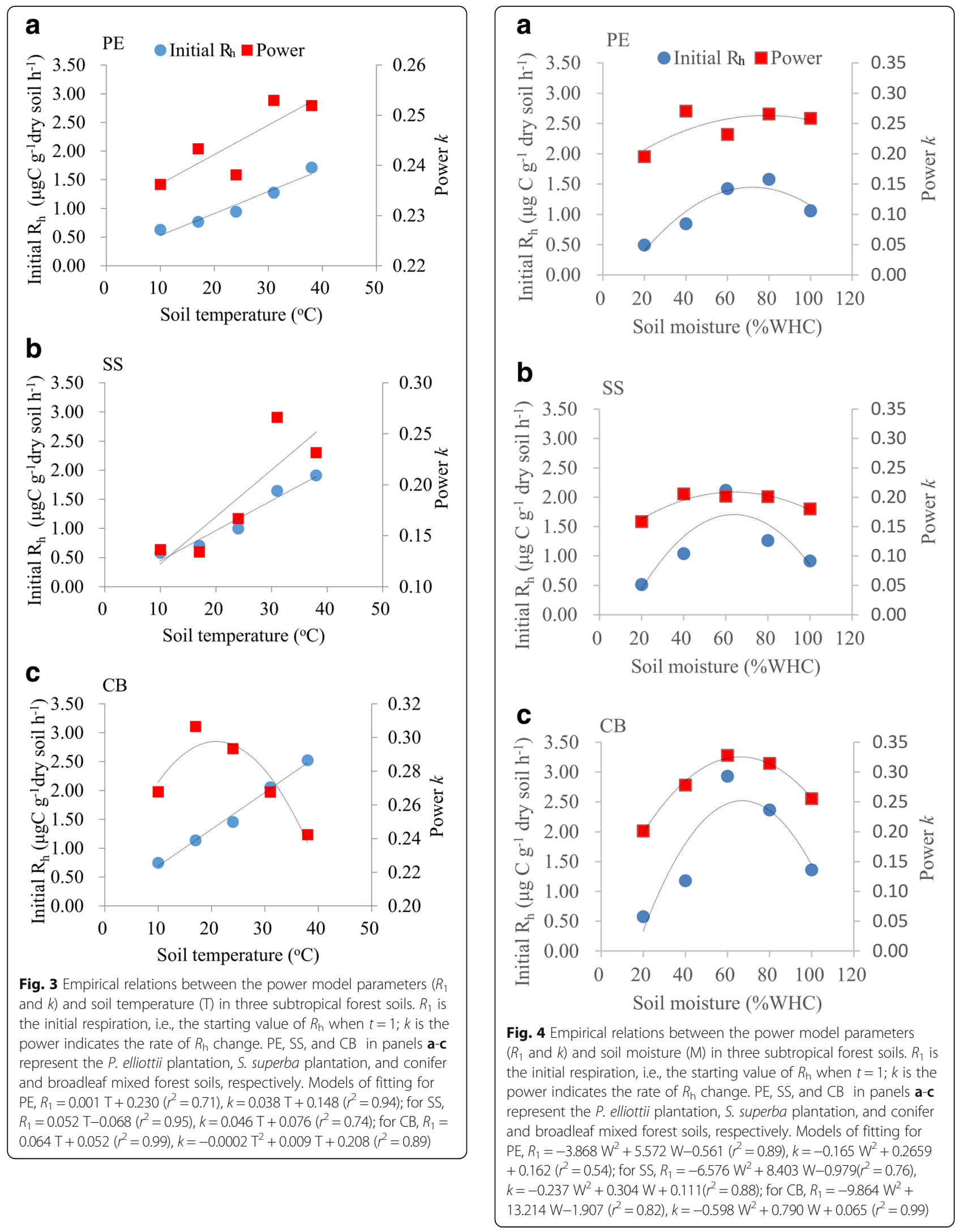




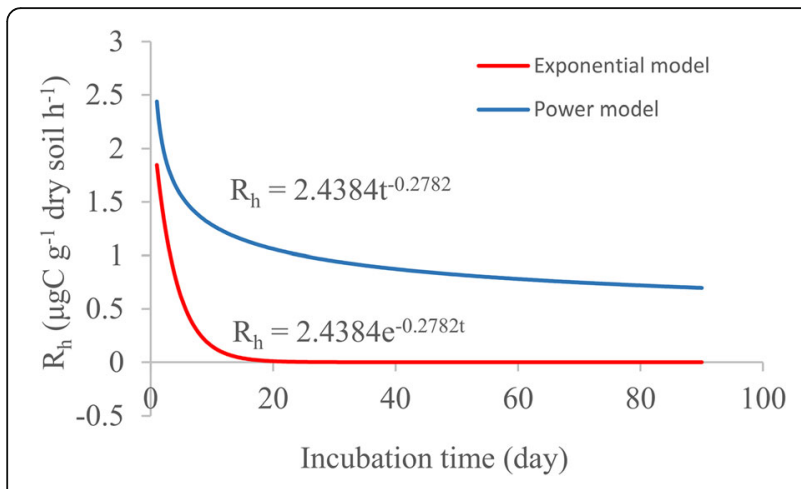

Fig. 5 Comparison of dynamic patterns between a power function model and an exponential model. The model parameters are adopted from Table 2 for the CB forest

With respect to soil moisture treatments, the two parameters of the power function model showed different response patterns compared with those to temperature treatments. At a low soil moisture (e.g., 20\% WHC), SOC decomposition may be limited by water availability. At a high soil moisture (e.g., 100\% WHC), it may be limited by oxygen availability. Thus, soil microbes are often more active at medium soil moistures (Bauer et al. 2008; Craine and Gelderman 2011; Davidson et al. 2012). This explains why the values of $R_{1}$ and $k$ were the highest when soil moisture was at $60 \% \mathrm{WHC}$ (Fig. 4). Relative to that of $R_{1}$, the response pattern of $k$ was less curving, indicating that $k$ was less sensitive to moisture changes.

Forest type had significant effects on $k$ but not on $R_{1}$. Previous studies reported that plant species and soil biological communities could affect soil respiration through altering soil physicochemical properties (Monokrousos et al. 2004; Wei et al. 2015). The three forests in this study differed in their dominant tree species and soil properties, with $\mathrm{CB}$ having the highest soil TOC, TN and TP, and SS having the lowest ones. Although we found no significant forest type effects on $R_{1}$, it did vary among forest types (Figs. 3 and 4). The mechanisms underlying the influence of forest type on the model parameters $R_{1}$ and $k$ need to be better understood in order to explain the $R_{\mathrm{h}}$ variations across ecosystem types.

\section{Conclusions}

Compared with the widely used exponential decay model, the power function model performed better in quantitatively describing the change of $R_{\mathrm{h}}$ with incubation time under a wide range of temperature $\left(10-38^{\circ} \mathrm{C}\right)$ and moisture (20-100\% WHC) conditions in three subtropical forest soils. The two key parameters $\left(R_{1}\right.$ and $\left.k\right)$ of the power function model had a linear relationship with temperature but a quadratic relationship with moisture. The empirical relations derived from this incubation study provide important insights for developing and parameterizing more mechanistic process-based ecosystem models. However, the generality of these empirical relations should be further tested under field conditions for the purpose of simulating soil $R_{\mathrm{h}}$ responses to climate changes in subtropical forests. Why and how the parameters vary with other soil properties such as substrate availability, microbial diversity and community composition, and the structural and functional properties of plant communities are the prior questions towards a better understanding to the mechanisms underlying the $R_{\mathrm{h}}$ responses to climate changes.

\section{Abbreviations}

BD: Soil bulk density; CB: Subtropical coniferous and broadleaf mixed forest; PE: Plantation of Pinus elliottii; SS: Plantation of Schima superba; TN: Total nitrogen; TOC: Total organic carbon; TP: Total phosphorus; WHC: Water holding capacity

\section{Acknowledgements}

We thank Ms. Chunqing Long for her assistant in field sampling and laboratory incubation, Mr. Brett Seybert and Dr. Guangcun Hao for their edits to the manuscript, and Dr. Yiqi Luo and three anonymous reviewers for their constructive comments that improved the manuscript.

\section{Funding}

This study was financially supported by the National Natural Science Foundation of China (31425005, 31290222 and 31130011) and the National Key Research and Development Program of China (2016YFC1403001). Preparation of this manuscript was partially supported by the USDA Evans-Allen and CBG projects.

\section{Authors' contributions}

$\mathrm{DH}$ and WS designed the study. WZ and JH conducted the laboratory experiment. WZ and DH analyzed the data. DH, WZ, and WS wrote the manuscript. All authors read and approved the final manuscript.

\section{Competing interests}

The authors declare no competing financial interests. The funders had no role in study design, data collection and analysis, decision to publish, or preparation of the manuscript.

\section{Author details}

${ }^{1}$ Institute of Environment and Sustainable Development in Agriculture, Chinese Academy of Agricultural Sciences, Beijing 100081, China. ${ }^{2}$ Key Laboratory for Agro-Environment, Ministry of Agriculture, Beijing 100081, China. ${ }^{3}$ Key laboratory of Vegetation Restoration and Management of Degraded Ecosystems, South China Botanical Garden, Chinese Academy of Sciences, Guangzhou 510650, China. ${ }^{4}$ University of Chinese Academy of Sciences, Beijing 100049, China. ${ }^{5}$ Department of Biological Sciences,

Tennessee State University, Nashville, TN 37209, USA.

Received: 17 November 2016 Accepted: 10 February 2017 Published online: 08 March 2017

\section{References}

Aber JD, Melillo JM, McClaugherty CA (1990) Predicting long-term patterns of mass loss, nitrogen dynamics, and soil organic matter formation from initial fine litter chemistry in temperate forest ecosystems. Can J Bot 68(10):2201-2208

Bauer J, Herbst M, Huisman JA, Weihermuller L, Vereecken H (2008) Sensitivity of simulated soil heterotrophic respiration to temperature and moisture reduction functions. Geoderma 145(s1-2):17-27

Berg B, McClaugherty C (2014) Plant litter: decomposition, humus formation, carbon sequestration. Springer Press, New York, pp 189-200, Chapter 9, models that describe litter decomposition

Blagodatskaya EV, Blagodatsky SA, Anderson T-H, Kuzyakov Y (2009) Contrasting effects of glucose, living roots and maize straw on microbial growth kinetics and substrate availability in soil. Eur J Soil Sci 60(2):186-197 
Bond-Lamberty B, Thomson AA (2010) Global database of soil respiration data. Biogeosciences 7(6):1915-1926

Craine JM, Gelderman TM (2011) Soil moisture controls on temperature sensitivity of soil organic carbon decomposition for a mesic grassland. Soil Biol Biochem 43(2):455-457

Curiel Yuste J, Baldocchi DD, Gershenson A, Goldstein A, Misson L, Wong S (2007) Microbial soil respiration and its dependency on carbon inputs, soil temperature and moisture. Global Change Biol 13(9):2018-2035

Curtin D, Beare MH, Hernadez-Ramirez G (2012) Temperature and moisture effects on microbial biomass and soil organic matter mineralization. Soil Sci Soc Am J 76(6):2055-2067

Dalias P, Anderson JM, Bottner P, Coûteaux MM (2001) Long-term effects of temperature on carbon mineralization processes. Soil Biol Biochem 33(7-8):1049-1057

Davidson EA, Belk E, Boone RD (1998) Soil water content and temperature as independent or confounded factors controlling soil respiration in a temperate mixed hardwood forest. Global Change Biol 4(2):217-227

Davidson EA, Janssens IA (2006) Temperature sensitivity of soil carbon decomposition and feedbacks to climate change. Nature 440(7081):165-173

Davidson EA, Samanta S, Caramori SS, Savage K (2012) The dual Arrhenius and Michaelis-Menten kinetics model for decomposition of soil organic matter at hourly to seasonal time scales. Global Change Biol 18(1):371-384

Deng Q, Hui D, Zhang D, Zhou G, Liu J, Liu S, Chu G, Li J (2012) Effects of precipitation increase on soil respiration: a three-year field experiment in subtropical forests in China. PLoS One 7(7):e41493. doi:10.1371/journal.pone.0041493

Fang C, Smith P, Moncrieff JB, Smith JU (2005) Similar response of labile and resistant SOM pools to changes in temperature. Nature 433(7021):57-59

Fierer N, Craine JM, McLauchlan K, Schimel JP (2005) Litter quality and the temperature sensitivity of decomposition. Ecology 86(2):320-326

García-Palacios P, Maestra FT, Kattge J, Wall DH (2013) Climate and litter quality differently modulate the effects of soil fauna on litter decomposition across biomes. Ecol Lett 16(8):1045-1053

Gholz HL, Wedin DA, Smitherman SM, Harmon ME, Parton WJ (2000) Long-term dynamics of pine and hardwood litter in contrasting environments: toward a global model of decomposition. Global Change Biol 6(7):751-765

Giardina CP, Ryan MG (2000) Evidence that decomposition rates of organic carbon in mineral soil do not vary with temperature. Nature 404(6780):858-861

Huang W, Schoenau JJ (1997) Mass loss measurements and statistical models to predict decomposition of leaf litter in a boreal aspen forest. Commun Soil Sci Plant Anal 28(11):863-874

Hui D, Jackson RB (2009) Assessing interactive responses in litter decomposition in mixed species litter. Plant Soil 314(1-2):263-271

Hui D, Luo Y (2004) Evaluation of soil $\mathrm{CO}_{2}$ production and transport in Duke Forest using a process-based modeling approach. Global Biogeochem Cycle 18(4):GB4029. doi:10.1029/2004GB002297

lqbal J, Hu RG, Lin S, Ahamadou B, Feng ML (2009) Carbon dioxide emissions from Ultisol under different land uses in mid-subtropical China. Geoderma 152(s1-2):63-73

Ise T, Moorcroft PR (2006) The global-scale temperature and moisture dependencies of soil organic carbon decomposition: an analysis using a mechanistic decomposition model. Biogeochemistry 80(3):217-231

Jenny H, Gessel SP, Bingham FT (1949) Comparative study of decomposition rates of organic matter in temperate and tropical regions. Soil Sci 68(6):419-432

Kirschbaum MUF (1995) The temperature dependence of soil organic matter decomposition, and the effect of global warming on soil organic storage. Soil Biol Biochem 27(27):753-760

Lee H, Fitzgerald J, Hewins DB, McCulley RL, Archer SR, Rahn T, Throop HL (2014) Soil moisture and soil-litter mixing effects on surface litter decomposition: a controlled environment assessment. Soil Biol Biochem 72(6):123-132

Li Z, Peng S, Rae DJ, Zhou G (2001) Litter decomposition and nitrogen mineralization of soils in subtropical plantation forests of southern China, with special attention to comparisons between legumes and non-legumes. Plant Soil 229(1):105-116

Luo Y, Wan S, Hui D, Wallace $L$ (2001) Acclimation of soil respiration to temperature in tallgrass prairie. Nature 413(6856):622-625

Meentemeyer V (1978) Macroclimate and lignin control of litter decomposition rates. Ecology 59(59):465-472

Monokrousos N, Papatheodorou EM, Diamantopoulos JD, Stamou GP (2004) Temporal and spatial variability of soil chemical and biological variables in a Mediterranean shrubland. Forest Ecol Manag 202(1-3):83-91

Nambu K, Van Hees PAW, Jones DL, Vinogradoff S, LundstrÖm US (2008) Composition of organic solutes and respiration in soils derived from alkaline and non-alkaline parent materials. Geoderma 144(3-4):468-477
Nottingham AT, Griffiths H, Chamberlain PM, Stott AW, Tanner EVJ (2009) Soil priming by sugar and leaf-litter substrates: a link to microbial groups. Appl Soil Ecol 42(3):183-190

Olson JS (1963) Energy storage and balance of producers and decomposers in ecological systems. Ecology 44(2):322-331

Parton WJ, Stewart WB, Cole CV (1988) Dynamics of C, N, P and S in grassland soils: a model. Biogeochemistry 5(1):109-131

Paul EA, Harris D, Collins HP, Schulthess U, Robertson GP (1999) Evolution of CO2 and soil carbon dynamics in biologically managed, row-crop agroecosystems. Appl Soil Ecol 11(1):53-65

Paustian K, Parton WJ, Persson J (1992) Modelling soil organic matter in organicamended and nitrogen-fertilized long-term plots. Soil Sci Soc Am J 56(2): 476-488

Piao S, Fang J, Ciais P, Peylin P, Huang Y, Sitch S, Wang T (2009) The carbon balance of terrestrial ecosystems in China. Nature 458(7241):1009-1013

Raich JW, Schlesinger WH (1992) The global carbon dioxide flux in soil respiration and its relationship to vegetation and climate. Tellus B 44(2):81-99

Reynolds JF, Kemp PR, Tenhunen JD (2000) Effects of long-term rainfall variability on evapotranspiration and soil water distribution in the Chihuahuan Desert: a modeling analysis. Plant Ecol 150(1):145-159

Richardson J, Chatterjee A, Jenerette GD (2012) Optimum temperatures for soil respiration along a semi-arid elevation gradient in southern California. Soil Biol Biochem 46(1):89-95

Shen W, Jenerette GD, Hui D, Phillips RP, Ren H (2008) Effects of changing precipitation regimes on dryland soil respiration and $\mathrm{C}$ pool dynamics at rainfall event, seasonal and interannual scales. J Geophys Res- Biogeosciences 113(G3):G03024. doi:10.1029/2008JG000685

Shen W, Reynolds JF, Hui D (2009) Responses of dryland soil respiration and soil carbon pool size to abrupt vs. gradual and individual vs. combined changes in soil temperature, precipitation, and atmospheric $\left[\mathrm{CO}_{2}\right]$ : a simulation analysis. Global Change Biol 15(9):2274-2294

Song M, Jiang J, Cao G, Xu X (2010) Effects of temperature, glucose and inorganic nitrogen inputs on carbon mineralization in a Tibetan alpine meadow soil. Eur J Soil Biol 46(6):375-380

Tan X, Chang S (2007) Soil compaction and forest litter amendment affect carbon and net nitrogen mineralization in a boreal forest soil. Soil Till Res 93(1):77-86

Thiessen S, Gleixner G, Wutzler T, Reichstein M (2013) Both priming and temperature sensitivity of soil organic matter decomposition depend on microbial biomass_-an incubation study. Soil Biol Biochem 57(3):739-748

Wei H, Chen X, Xiao G, Guenet B, Vicca S, Shen W (2015) Are variations in heterotrophic soil respiration related to changes in substrate availability and microbial biomass carbon in the subtropical forests? Scientific Reports 5: 18370. doi:10.1038/srep18370

Wu C, Yi C, Wang J, Wang S (2006) Estimation of turnover and equilibrium of soil organic matter using a mathematical approach. Pedosphere 16(5):634-645

Zhang D, Hui D, Luo Y, Zhou G (2008) Rates of litter decomposition in terrestrial ecosystems: global patterns and controlling factors. J Plant Ecol 1(2):85-93

Zhou W, Hui D, Shen W (2014) Effects of soil moisture on the temperature sensitivity of soil heterotrophic respiration: a laboratory incubation study. PLoS One 9(3):e92531. doi:10.1371/journal.pone.0092531

\section{Submit your manuscript to a SpringerOpen ${ }^{\odot}$ journal and benefit from:}

- Convenient online submission

- Rigorous peer review

- Immediate publication on acceptance

- Open access: articles freely available online

- High visibility within the field

- Retaining the copyright to your article

Submit your next manuscript at springeropen.com 